\title{
Fiscal Stimulus: Solution for arresting the economic slowdown
}

\author{
Pradeep Kumar Panda* \\ Department of Economics, India.
}

*Corresponding author: Pradeep Kumar Panda, Department of Economics, India.

Received Date: September 032019

Published Date: October 11, 2019

\section{Opinion}

Markets overcame global shocks from US President Donald Trump's trade war to end positive thanks to Union Finance Minister Nirmala Sitharaman's first of three economic sentiment-boosters delivered recently.

And that fact frames the key question on the near future of the India economic story-can the positive of government-created activity-multipliers continue to overcome the negative of global economic depressors? And, if so, by how much?

A Goldman Sachs (GS) research report, 'India's Economic Slowdown: This Episode is Different', gives very useful pointers to anyone considering this most consequential question.

GS analysis shows around 50\% of the slowdown is explained by tight liquidity and low consumer confidence, and just over $40 \%$ by slowing global economic activity. Another important finding is that the absence of a fiscal stimulus explains around $7 \%$ of the slowdown. Policy choices and dilemmas are clear from these numbers. The net effect of domestic boosters may end up being a small positive, or not even that, depending on the impact of the global drag.

Basically, given that India is a taker and not a player in the global economy, and given the reasonable assumption that the worst effect of the Trump trade war hasn't yet played out, the economy desperately needs to keep consumer confidence up, and credit to flow far more freely-with the government not ruling out the option of a higher fiscal spend down the line.

Indian Govt's package is a good start, because it squarely addresses some of these aspects. The withdrawal of the two bad taxes-on capital gains and startup funding-and attempts to encourage more retail credit flows and energize aggregate demand, should impact economic sentiments and, therefore, consumer confidence.
Front-loading bank recapitalization and other tweaks in the credit supply chain, as well as the promised quick disbursal of tax refunds and vendor payments to the private sector, plus Sitharaman's repeated emphases on saner tax administration, should impact credit flow, sentiments and, therefore, activity in the economic production side.

We don't know what the finance minister's other two sets of announcements will entail. But the fact that there's recognition that more is needed is good-indeed, even more than what GoI does shortly may be required, given specifics of this round of slowdown. GS research shows this slowdown has been the longest in recent times- around 18 months starting early 2018.

That the slowdown predated the Infrastructure Leasing \& Financial Services (IL\&FS)-induced non-banking financial company (NBFC) crisis. That consumption has not just been the biggest drag, but that it also started falling across some of its sub-segments before 2018. And that while much attention is focused on the auto sector, which contributes a third of the consumption slowdown, non-auto consumption items are responsible for twice as much.

These findings seem to indicate that domestic consumption will require a sustained and big policy push to substantively revive. And that's after assuming credit flows to economic agents revive significantly and stay so. Therefore, given the big consumption problem, given available policy options for the government, and given the huge impact of the global economic slowdown, the need for a consumption-boosting Keynesian multiplier may be more acute than the government may like.

A tiny departure from the fiscal carefulness has already happened via the decision that GoI will start replacing its old cars with new ones. Over the next three-four quarters, bigger and more creative fiscal options may have to be-or, indeed, should beconsidered. 
The Reserve Bank of India (RBI) board decided to transfer Rs 1.76 lakh crore of its 'excess capital' to the government-this is nearly double the Rs 90,000 crore central bank transfer assumed in 2019-20 Budget, however, around Rs 28,000 crore is already accounted for as interim dividend for 2018-19. It would be smart to spend the extra amount in bang-for-buck ways, aimed at the fastest and deepest impact on consumption expenditure.

But aside that, the finance ministry must not right now be rigid on the fiscal deficit. Inflation is low, consumption is hurting, exports are in dumps, and investment has been flat for a while. So, the government should proactively plan a fiscal boost and execute it as a sort of an emergency economic measure, should, for example, the consumption slowdown continues to drag everything else down.

GS concludes its analysis by saying that assuming a significant rise in consumer confidence and easier liquidity/credit conditions, economic activity may rise by next March. The rise is modest, and global slow growth and 'negative fiscal impulses' are likely to be the main drags. GoI can change only the second of these two.

So, as we wait for Sitharaman's next sets of announcements, and the depressing FY20 first-quarter GDP estimate of 5\% GDP, we should hope the Government of India doesn't rule out fiscal unorthodoxy. Fiscal Stimulus is the solution for arresting the slowdown.

\section{Acknowledgements}

None.

\section{Conflict of Interest}

No conflict of interest. 